\title{
Hydrodynamic Analysis of a Semi-submersible Wind-Tidal Combined Power Generation Device
}

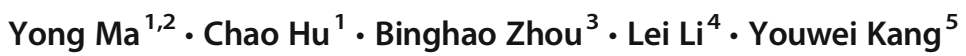 \\ Received: 12 October 2017 / Accepted: 1 November 2018 / Published online: 22 March 2019 \\ (C) The Author(s) 2019
}

\begin{abstract}
Energy shortages and environmental pollution are becoming increasingly severe globally. The exploitation and utilization of renewable energy have become an effective way to alleviate these problems. To improve power production capacity, power output quality, and cost effectiveness, comprehensive marine energy utilization has become an inevitable trend in marine energy development. Based on a semi-submersible wind-tidal combined power generation device, a three-dimensional frequency domain potential flow theory is used to study the hydrodynamic performance of such a device. For this study, the RAOs and hydrodynamic coefficients of the floating carrier platform to the regular wave were obtained. The influence of the tidal turbine on the platform in terms of frequency domain was considered as added mass and damping. The direct load of the tidal turbine was obtained by CFX. FORTRAN software was used for the second development of adaptive query workload aware software, which can include the external force. The motion response of the platform to the irregular wave and the tension of the mooring line were calculated under the limiting condition (one mooring line breakage). The results showed that the motion response of the carrier to the surge and sway direction is more intense, but the swing amplitude is within the acceptable range. Even in the worst case scenario, the balance position of the platform was still in the positioning range, which met the requirements of the working sea area. The safety factor of the mooring line tension also complied with the requirements of the design specification. Therefore, it was found that the hydrodynamic performance and motion responses of a semi-submersible wind-tidal combined power generation device can meet the power generation requirements under all design conditions, and the device presents a reliable power generation system.
\end{abstract}

Keywords Power generation device $\cdot$ Coupling hydrodynamic analysis $\cdot$ AQWA $\cdot$ Mooring line tension $\cdot$ Motion response $\cdot$ Hydrodynamic analysis · Power generation device

\section{Article Highlights}

- The design of the platform can survive in harsh sea environment. The semi-submersible platform can keep in position when one mooring line breaks.

- The multi-component mooring system can effectively reduce the tension force of the mooring line without large movement.

- A coupled numerical method based on AQWA was proposed for such a platform.

Lei Li

lei.li@strath.ac.uk

1 College of Shipbuilding Engineering, Harbin Engineering University, Harbin 150001, China

2 School of Marine Engineering and Technology, Sun Yat-sen University, Guangzhou 518000, China

3 CHEC Dredging Co., Ltd, Shanghai 200136, China

4 Department of Naval Architecture, Ocean \&Marine Engineering, University of Strathclyde, Glasgow, UK

5 National Engineering Lab, CIMC Offshore Ltd, Shenzhen 518000, China

\section{Introduction}

Research on the multi-power complementary ocean platforms has virtually just begun. Most of the work is still in the conceptual design or pre-project demonstration stage. At present, many early explorations of multi-power complementary designs have come upon a common core problem, i.e., resolving the interaction mechanisms between the multiple subsystems. In response to this problem, some preliminary research results have emerged: Zhou Nianfu studied the load and efficiency of turbines in oscillating floating platforms (Sheng et al. 2015). Li Yan studied the influence of the turbine array arrangement on turbine power generation efficiency (Li 2017b). Li Tengfei explored the coupling interaction mechanism between turbine and floating tidal platform (Li 2017a). Tomasicchio's numerical results on floating platforms (Tomasicchio et al. 2017) and Riefolo's numerical results 
Table 1 Environmental parameters of Zhoushan islands

\begin{tabular}{lllll}
\hline Water depth & Submarine soil & Flow rate $/\left(\mathrm{m} \cdot \mathrm{s}^{-1}\right)$ & Water depth $/ \mathrm{m}$ & Maximum tidal range $/ \mathrm{m}$ \\
\hline Self-storage condition & Rock & 4 & 40 & 3 \\
\hline
\end{tabular}

on fixed platforms (Riefolo et al. 2016) showed the advantages and disadvantages of fixed platforms and floating platforms. The fixed platform is more stable but less flexible and has a greater impact on marine ecosystems. The floating platform is flexible and easy to dismantle, thus having little impact on the marine ecosystem.

Based on the relevant research results (Christensen et al. 2015; Chozas 2012; Greaves et al. 2014; Tuitman et al. 2012; Lin and Yue 1991; Mohanty et al. 2016), this paper considers the interaction between the turbine system and the carrier platform in the process of hydrodynamic analysis. In the analysis of hydrodynamic performance of the platform, the main concern is the motion response of the platform to ocean wave action and the load-bearing system. The time-domain hydrodynamic analysis based on the N-S equation (Marquis et al. 2012; Pérez-Collazo et al. 2015; Quevedo et al. 2013; Qi et al. 2011) can give the most intuitive and detailed analytical results, although the calculation process is lengthy and the processing of the results is more complex. Another boundary element method analyzes the hydrodynamics directly from the frequency domain (Deng 2011; Guo and Liang 2013; Jiang 2012). Because it is faster to calculate, and provides the design of the required important frequency domain parameters, its use is more common. In this paper, the research is based on the semi-submersible wind-tidal combined power generation platform. In the regular wave, the boundary element method is used to analyze the hydrodynamic analysis in the frequency domain, and the hydrodynamic parameters such as radiation damping, additional mass, and amplitude response operator (RAO) are obtained. To a certain extent, the boundary element method reveals the platform's kinetic performance and prepares it for subsequent time-domain calculations and in-depth analysis. Then, based on the indirect time-domain analysis method (Li et al. 2000; Ma et al. 2016; Sheng et al. 2008; Sheng et al. 2014), we consider the coupling calculation of the carrier, turbine, and mooring systems. The adaptive query workload aware (AQWA) software was developed with FORTRAN programming (ANSYS AQWA 2013),

Table 2 Main dimensions of the platform

\begin{tabular}{lllll}
\hline Length & Breadth & Depth & Draft & $\begin{array}{l}\text { Unit: } \mathrm{m} \\
\text { Freeboard }\end{array}$ \\
\hline 28 & 30 & 10.2 & 7.5 & 2.7 \\
\hline
\end{tabular}

taking into account all additional steady and unsteady forces, and simulating the time-domain coupling motion of the wind-tidal combined power generation device under extreme operating conditions, to obtain the motion response of the platform and the force of the mooring system under different working conditions.

\section{Computational Theory}

\subsection{Decomposition of Velocity Potential and Boundary Conditions}

Solving for velocity potential in the flow field is the key to determine the movement of the floating marine structure in response to waves (Wang 2011; Zhang et al. 2013). From the micro-amplitude wave hypothesis, we can see that the total velocity potential in the flow field around the floating body includes the incident potential, the radiation potential, and the diffraction potential, as follows:

$$
\begin{gathered}
\Phi(x, y, z, t)=\Phi_{0}(x, y, z, t)+\sum_{1}^{6} \Phi_{i}(x, y, z, t) \\
+\Phi_{7}(x, y, z, t)
\end{gathered}
$$

where $\Phi(x, y, z, t)$ represents the total velocity potential for fluid movement around the structure; $\Phi_{0}(x, y, z, t)$ represents the incident potential; $\Phi_{i}(x, y, z, t)$ represents radial potential of the ' $i$-mode'; and $\Phi_{7}(x, y, z, t)$ represents the diffraction potential.

According to frequency domain analysis theory, free surface conditions include kinematic conditions and kinetic conditions (Zhu et al. 2002; Zhang et al. 2010). At the same time, in order to meet closed-boundary conditions, we must set the infinite distance boundary conditions, that is, radiation conditions.

Then, the frequency domain velocity potential $\phi$ of the solution conditions can be expressed as:

$$
\left\{\begin{array}{l}
{[L]: \nabla^{2} \phi=0} \\
{[F]: \frac{\partial^{2} \phi}{\partial^{2} t}+g \frac{\partial \phi}{\partial z}=0} \\
{[S]: \frac{\partial \phi}{\partial n}=\boldsymbol{V}(t) \cdot \boldsymbol{n}} \\
{[B]: \lim _{z \rightarrow \infty} \frac{\partial \phi}{\partial z}=0} \\
{[R]: \lim _{R \rightarrow \infty} \sqrt{R}\left(\frac{\partial \phi}{\partial R}-i k \frac{\partial \phi}{\partial t}\right)=0}
\end{array}\right.
$$

where $g$ represents gravitational acceleration; $k$ represents the wave number of the incident wave, and $k=\omega^{2} / g$. 
Table 3 Parameters of the tidal turbine

\begin{tabular}{llll}
\hline $\begin{array}{l}\text { Design current rate } /\left(\mathrm{m} \cdot \mathrm{s}^{-1}\right) \\
2.5\end{array}$ & Maximum current rate $/ \mathrm{m}$ & Diameter $/ \mathrm{m}$ & Installed capacity $/ \mathrm{kW}$ \\
& 40 & 6 & 110 \\
Chord length $/ \mathrm{m}$ & Air foil & Blade number & Span length $/ \mathrm{m}$ \\
0.96 & NACA0018 & 2 & 8 \\
\hline
\end{tabular}

Table 4 Parameters of the wind turbine

\begin{tabular}{lllll}
\hline Installed capacity $/ \mathrm{kW}$ & Impeller diameter $/ \mathrm{m}$ & Tower height $/ \mathrm{m}$ & Cut in $/$ out wind speed $/\left(\mathrm{m} \cdot \mathrm{s}^{-1}\right)$ & Rated wind speed $/\left(\mathrm{m} \cdot \mathrm{s}^{-1}\right)$ \\
200 & 27.5 & 25 & $3.5 / 25$ & 12 \\
& & & Turbine weight $/ \mathrm{t}$ \\
Limited wind speed $/\left(\mathrm{m}^{-1} \mathrm{~s}^{-1}\right)$ & Impeller weight $/ \mathrm{t}$ & Tower weight $/ \mathrm{t}$ & Cabin weight $/ \mathrm{t}$ & 3 \\
59.5 & 3 & 24 & 6 & 3 \\
\hline
\end{tabular}

\subsection{First-Order Wave Force, Second-Order Wave Force}

The three-dimensional potential flow theory is used to analyze the floating marine structures under the action of regular waves. We make the following assumptions:

(1) The floating ocean structure movement produces a radiant force consisting of two parts of the mass force and the radiation damping force;

(2) The wave excitation force consists of incident wave force and diffraction wave force;

(3) The first wave force of the floating marine structure consists of two parts: the radiation force and the wave excitation force, and can be linearly superimposed.

The first-order wave force of floating body is:

$F_{j}=-\iint_{S} p n_{j} \mathrm{~d} S=-\int_{S} \mathrm{i} \omega \rho\left(\phi_{i}+\phi_{D}\right) n_{j} \mathrm{~d} S$

where $F_{j}$ represents the wave force in the $j$ direction; $S$ is the wet surface area of the floating body; $\phi_{D}$ is the diffraction velocity potential; $\phi_{i}$ represents velocity potential of the i-movement; $n_{j}$ represents the movement in $j$ direction; $\omega$ is the incident wave frequency; $h$ is the water depth; $k$ is the wave number of the incident wave. $\omega$ satisfies the following equation:

$\omega^{2}=g k \tanh (k h)$

Table 5 Parameters of anchor chains

\begin{tabular}{lllll}
\hline Material & $\begin{array}{l}\text { Length/ } \\
\mathrm{m}\end{array}$ & $\begin{array}{l}\text { Diameter/ } \\
\mathrm{mm}\end{array}$ & $\begin{array}{l}\text { Mass per unit } \\
\text { length/ } \\
\left(\mathrm{kg} \cdot \mathrm{m}^{-1}\right)\end{array}$ & $\begin{array}{l}\text { Fracture } \\
\text { load/kN }\end{array}$ \\
\hline $\begin{array}{l}\text { R4 unstudded } \\
\text { cable }\end{array}$ & 200 & 58 & 67 & 3628 \\
\hline
\end{tabular}

In this paper, the far-field method is used to solve the average second-order wave drift and torque. The average second-order wave drift is calculated as follows:

$$
\begin{aligned}
F_{\text {wave }}^{(2)} & =-\oint_{W L} 0.5 \rho g \xi^{2}{ }_{r} \boldsymbol{n} \mathrm{d} l+\iint_{S_{0}} 0.5 \rho|\nabla \Phi|^{2} \boldsymbol{n} \mathrm{d} S \\
& +\iint_{S_{0}} \rho\left(X \cdot \nabla \frac{\partial \Phi}{\partial t}\right) \boldsymbol{n} \mathrm{d} S+M_{S} \cdot R \cdot \ddot{X} g
\end{aligned}
$$

The average second-order wave drift moment is calculated as follows:

$$
\begin{aligned}
M_{\mathrm{wave}}^{(2)} & =-\oint 0.5 \rho g \xi^{2}{ }_{r}(\boldsymbol{x} \times \boldsymbol{n}) \cdot \mathrm{d} l \\
& +\oiint 0.5 \rho|\nabla \Phi|^{2}(\boldsymbol{x} \times \boldsymbol{n}) \mathrm{d} S \\
& +\oiint \rho\left(X \cdot \nabla \frac{\partial \Phi}{\partial t}\right)(\boldsymbol{x} \times \boldsymbol{n}) \mathrm{d} S+I_{S} \cdot R \cdot \ddot{X} g
\end{aligned}
$$

where $F^{(2)}$ wave is the average second-order wave drift force; $M_{\text {wave }}^{(2)}$ is the average second-order wave drift moment; $\xi_{r}$ is the wave height; $S_{o}$ is the wet surface area of the buoy; $X$ is the floating motion displacement; $M_{s}$ is the floating mass; $R$ is the floating body rotation matrix; and $\ddot{X} g$ is the acceleration at the center of gravity of the platform.

\subsection{Hydrodynamic Coefficient of the Tidal Turbine}

Based on Newton's second law, the equation of motion of the floating carrier can be expressed as:

$$
\begin{array}{r}
\boldsymbol{M}_{k j} \ddot{\eta}_{j}=-\boldsymbol{C}_{k j} \eta_{j}-\sum_{j=1}^{6}\left(\mu_{k j} \ddot{\eta}_{j}+\lambda k \dot{k j} \eta_{j}\right)+\boldsymbol{f}_{k} \mathrm{e}^{\mathrm{i} \omega t} \\
(k=1,2 \ldots 6)
\end{array}
$$

where $\eta, \dot{\eta}_{j}, \ddot{\eta}_{j}$ are the displacement, velocity, and acceleration, respectively, of the floating carrier. $\boldsymbol{M}_{k j}$ is the generalized structural mass matrix of the floating carrier. $\boldsymbol{C}_{k j}$ is the restoring force matrix. $\mu_{k j}, \lambda_{k j}$ is the added mass and damping. $f_{k}$ is 
Table 6 Wind turbine load

The total thrust of the wind turbine and the tower $/ \mathrm{kN}$

100 1700

the radiation force acting on the floating carrier.

The hydrodynamic influence of the turbine on the floating carrier can be considerd as added mass and damping. The added mass and damping can be obtained by forced oscillation simulation (Zhang et al. 2013). The hydrodynamic coefficient can be added to the equation by second development of the AQWA Userfoce. The external force can be included in the calculation model by the uerforce dynamic link library.

The load of the tidal turbine can be dealt with by linear theory when the tidal turbine oscillates in the open water (the turbine is fixed with the main shaft). The hydrodynamic parameter can be divided into the uniform flow hydrodynamic parameter, the damping parameter, and the added mass parameter.

$c_{x x} \approx c_{x x}^{F}(\lambda \theta)+\eta_{x x}(\lambda \theta) \bar{\mu}+m_{x x}(\lambda \theta) \bar{a}$

$c_{y x} \approx c_{y x}^{F}(\lambda \theta)+\eta_{y x}(\lambda \theta) \bar{\mu}+m_{y x}(\lambda \theta) \bar{a}$

where $c_{x x}$ is the thrust coefficient in the longitudinal direction because of the oscillation. $c_{y x}$ is the lateral force coefficient in the transverse direction because of the oscillation. The hydrodynamic coefficient can be obtained by the least square

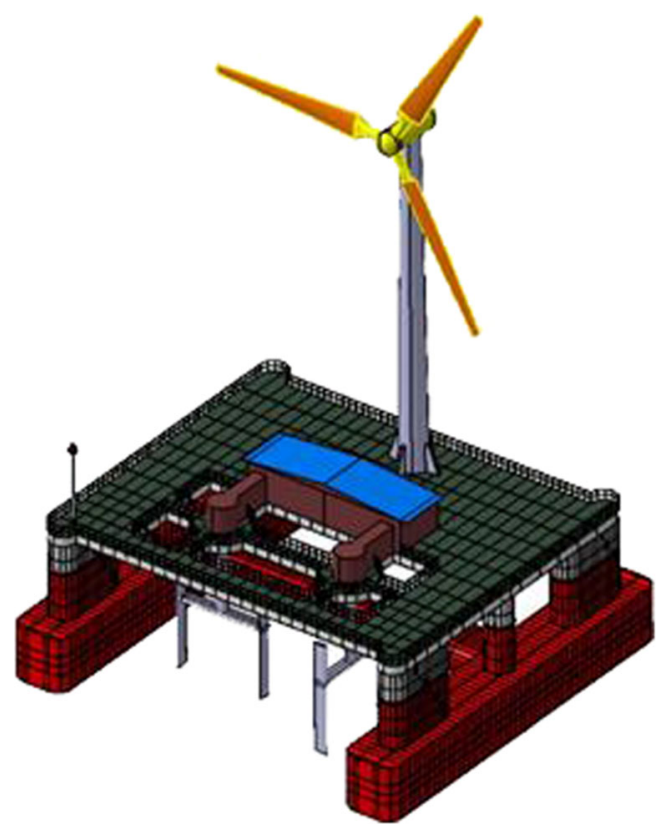

Fig. 1 Wind-tidal combined power generation platform

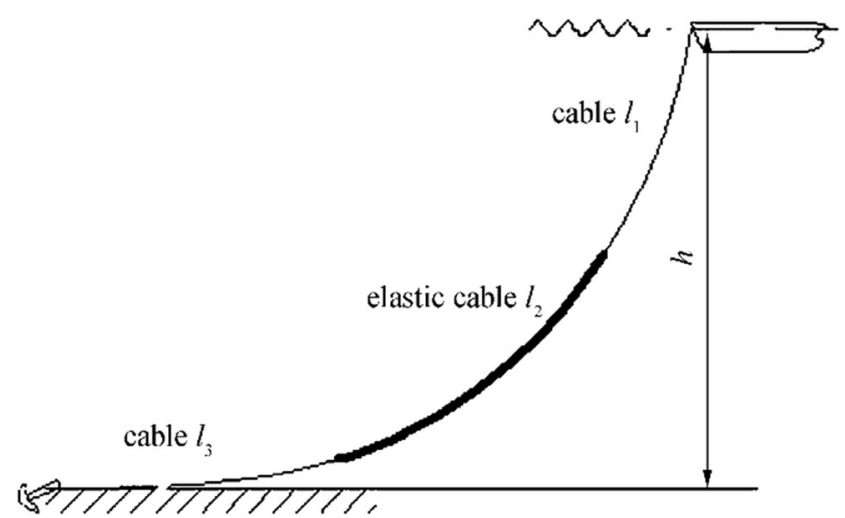

Fig. 2 Structure of the mooring line

method. Tables 1, 2, 3, 4, 5 and 6 give the hydrodynamic coefficient in the form of series.

\section{Numerical Calculation and Result Analysis}

\subsection{Model Design}

The offshore wind energy and ocean current energy in Zhou Shan are more abundant than in any other place in China. The tidal energy density of the JinTang waterway and GuiShan waterway ranges from 24 to $26 \mathrm{~kW} / \mathrm{m}^{2}$. Meanwhile, the annual mean wind speed can be as much as $6.9 \mathrm{~m} / \mathrm{s}$. Therefore, the Zhou Shan islands have been chosen as the design site. Detailed environmental parameters of the ZhouShan islands are shown in Table 1.

The design of the platform is mainly drawn from the CCS Classification of offshore mobile platforms. The main structure of the platform is shown Fig. 1. In order to make full use of the platform space, a $220 \mathrm{~kW}$ wind turbine and double $110 \mathrm{~kW}$ water turbines were selected. The total capacity of the wind-tidal combined power generation device was up to

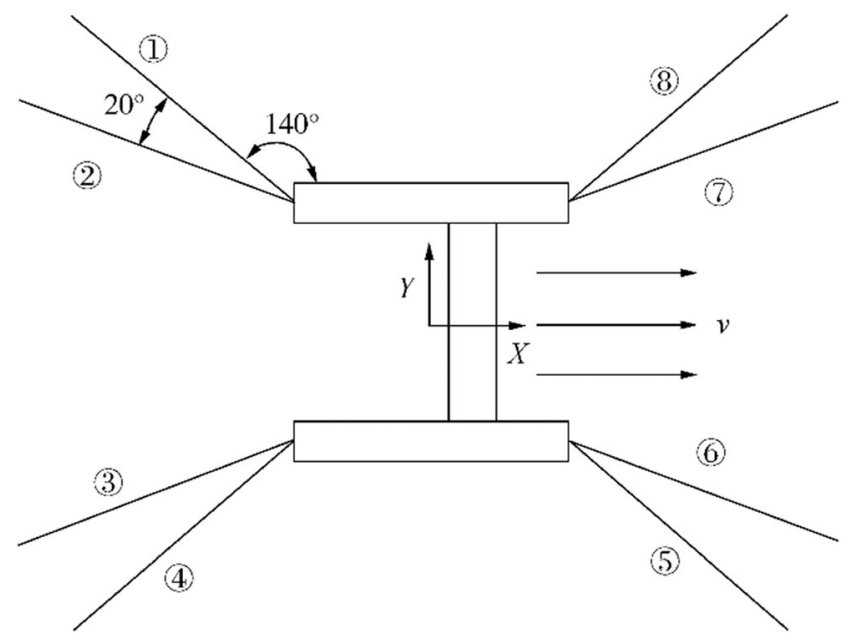

Fig. 3 Mooring design 


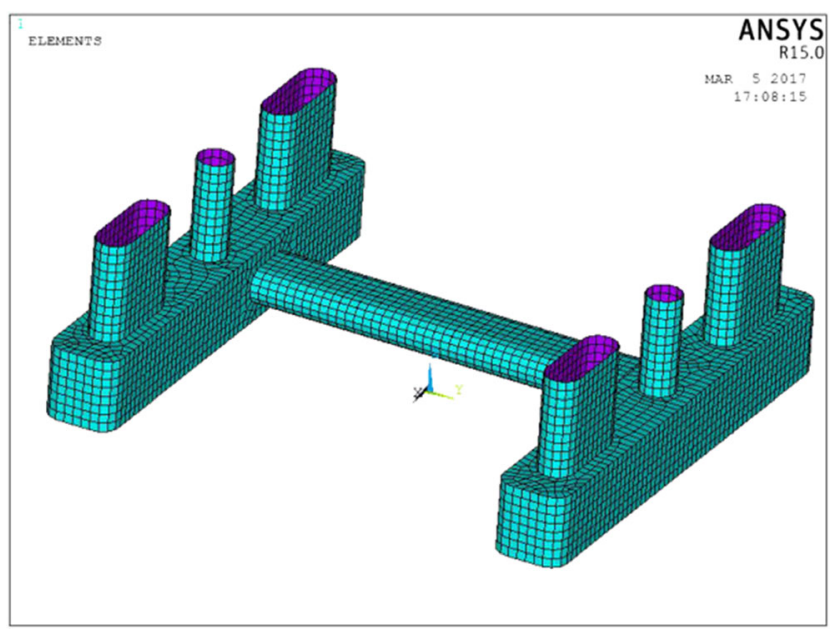

Fig. 4 AQWA calculation model

$420 \mathrm{~kW}$. Main dimensions and total weight of the platforms are shown in the Table 2.

The detailed parameters of the tidal turbines and wind turbines are shown in Tables 3 and 4 .

The operational depth of the device was $40 \mathrm{~m}$. The catenary part of the mooring line was very short. The deformation of the mooring line was not able to resist the influence of external forces. The operation of the turbines led to a huge horizontal load and overturning moment on the platform. Tension in the mooring line was significant and the mooring line had the risk of breakage. Therefore, elastic cable, having the advantage of lower weight, was used. Compared with anchor chains, the elastic cable could provide more buffering stress and tensile strength at the same length. Figures 2 and 3 show the structure of the mooring line and mooring design, respectively. Figures 2 and 3 also show the structure of the mooring line and the mooring design of the platform. The detailed parameters of the anchor chain are shown in Table 3.

\subsection{Numerical Model}

AQWA in ANSYS is a simulation tool for the shipping and marine engineering industries. It is used to calculate the hydrodynamic performance of ship and marine engineering. It has a wide range of functions, high precision, and userfriendly interface. It has been widely used for user engineering verification. Our frequency domain analysis used AQWA software. As we can see from Fig. 4, the default ship direction

Table $7 \quad C_{x x}$ hydrodynamic coefficient

\begin{tabular}{lllllllllll}
\hline$\lambda$ & $c_{x x}^{0}$ & $c_{x x}^{1}$ & $\psi_{x x}^{1}$ & $n_{x x}^{0}$ & $n_{x x}^{1}$ & $\psi_{n, x x}^{1}$ & $m_{x x}^{0}$ & $m_{x x}^{1}$ & $\psi_{m, x x}^{1}$ \\
\hline 3 & -1.09 & -1.16 & -91.85 & 2.57 & -2.59 & 77.14 & 0.16 & -0.03 & 56.74 \\
\hline
\end{tabular}

Table $8 C_{y x}$ hydrodynamic coefficient

\begin{tabular}{lllllllllll}
\hline$\lambda$ & $c_{y x}^{0}$ & $c_{y x}^{1}$ & $\psi_{y x}^{1}$ & $n_{y x}^{0}$ & $n_{y x}^{1}$ & $\psi_{n, y x}^{1}$ & $m_{y x}^{0}$ & $m_{y x}^{1}$ & $\psi_{m, y x}^{1}$ \\
\hline 3 & 0.09 & -1.02 & 12.88 & -0.09 & -2.64 & -161.17 & 0.03 & -0.01 & 121.27
\end{tabular}

in the AQWA was along the $X$ axis. The grid size was set to $0.5 \mathrm{~m}$ in the calculation process and the number of meshes was 6193 .

\subsection{Design Conditions}

The limiting conditions (one mooring line breakage) were calculated to test the performance of the floating carrier. Table 1 shows the environmental parameters of the designed sea area. Table 7 shows the wind turbine load, which is assumed to act on the center of gravity via the thrust and bending moment. The direct load of tidal turbines was time-varying and added to the model by userforce. Tables 7, 8, 9 and 10 show the water turbine hydrodynamic coefficient.

\subsection{Frequency Domain Motion Response}

The amplitude response operator (RAO) is an important parameter reflecting the motion response of the tidal current power generation platform. In this paper, the RAOs derived from the calculation process are given in the form of frequency function. The design water depth is $40 \mathrm{~m}$. Draft of the platform is $7.5 \mathrm{~m}$. The calculation frequencies range from 0 to $3 \mathrm{rad} / \mathrm{s}$. The frequency calculation step is $0.1 \mathrm{rad} / \mathrm{s}$. In addition, since the floating carrier is symmetrical about the $x-z$ plane, incident wave directions at $0^{\circ}, 30^{\circ}, 60^{\circ}, 90^{\circ}, 120^{\circ}$, $160^{\circ}$, and $180^{\circ}$ are calculated in the calculation process. Figure 2 shows the RAOs of six degrees of freedom when the wave angle is changed from 0 to $90^{\circ}$.

As we can see from Figs. 5(a) and 5(b), the response variation tendencies of the device in surge and sway were similar, with the response increasing at first and then decreasing. The surge response reached its greatest value when the incoming wave angle was $0^{\circ}$. The sway response reached its greatest value when the incoming wave angle was $90^{\circ}$. As we can see from Fig. 5(c), the heave response reached its greatest value when the incoming wave angle was $90^{\circ}$. As we can see from Fig. 5(d), the rolling response increased with increasing

Table $9 C_{x y}$ hydrodynamic coefficient

\begin{tabular}{lllllllllll}
\hline$\lambda$ & $c_{x y}^{0}$ & $c_{x y}^{1}$ & $\psi_{x y}^{1}$ & $n_{x y}^{0}$ & $n_{x y}^{1}$ & $\psi_{n, x y}^{1}$ & $m_{x y}^{0}$ & $m_{x y}^{1}$ & $\psi_{m, x y}^{1}$ \\
\hline 3 & -122 & -1.28 & -91.24 & -0.13 & -1.87 & 176.51 & -0.03 & -0.09 & -178.55 \\
\hline
\end{tabular}




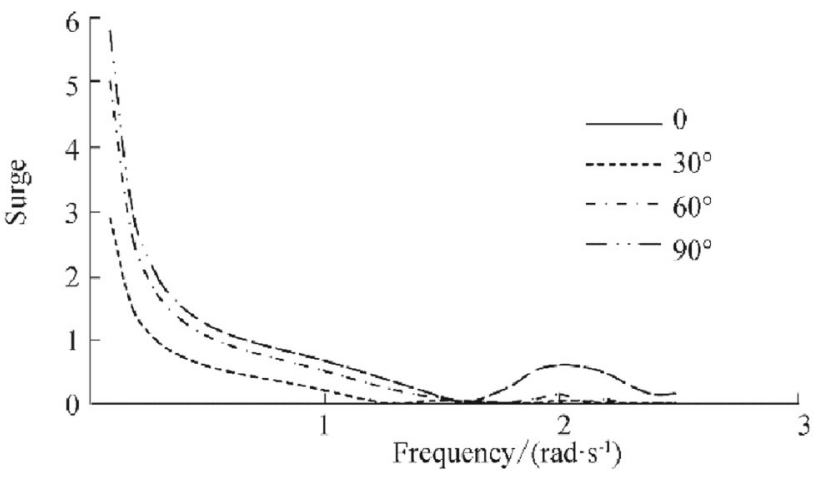

(a) RAO in surge

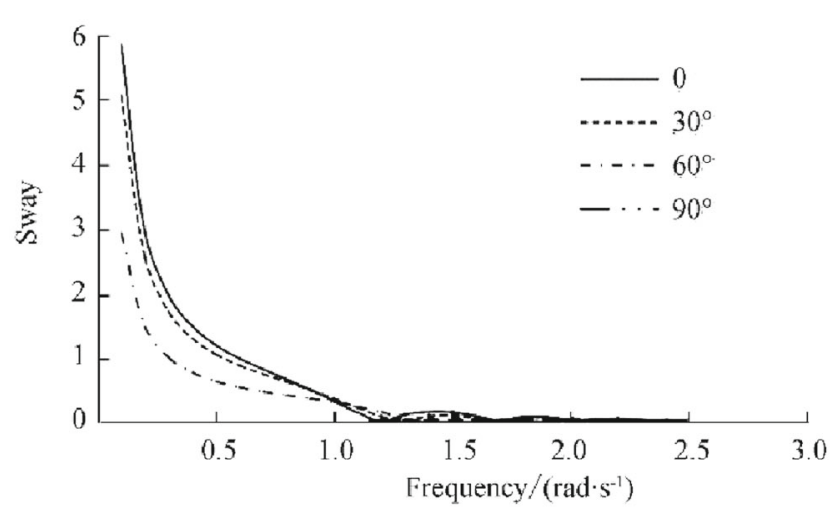

(b) RAO in sway

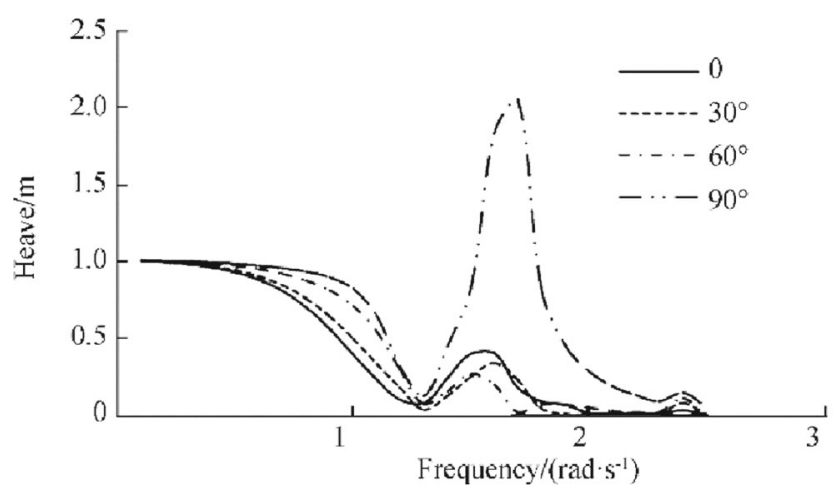

(c) RAO in heave

Fig. 5 Motion response in frequency domain

wave period at first, and then decreased. The rolling response reached its smallest value when the wave angle was $0^{\circ}$. As we can see from Fig. 5(e), the pitch response of the device increased with increasing wave period, in general, and then decreased. The pitch response had the smallest value when the wave angle was $90^{\circ}$. As we can see from Fig. 5(f), the yaw response of the device increased with increasing wave period at first, then decreased when the wave angle was $30^{\circ}$ and $60^{\circ}$. The pitch response of the device was very small when the wave

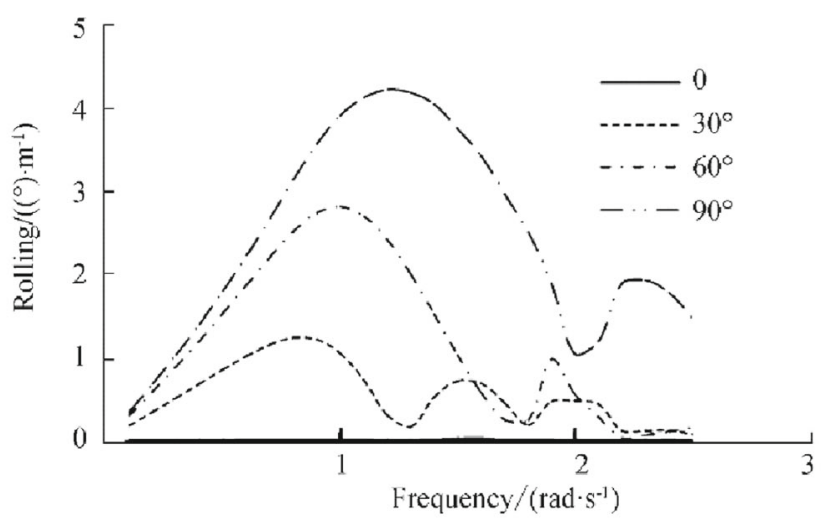

(d) RAO in roll

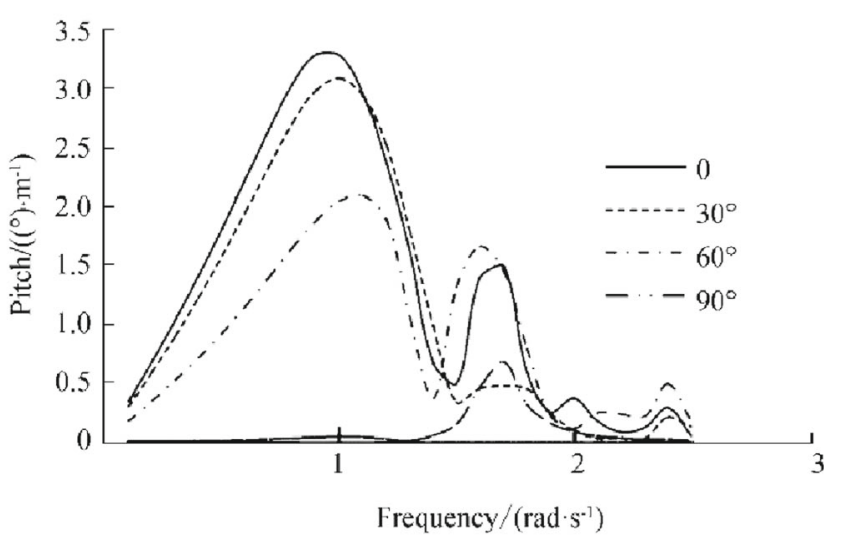

(e) RAO in pitch

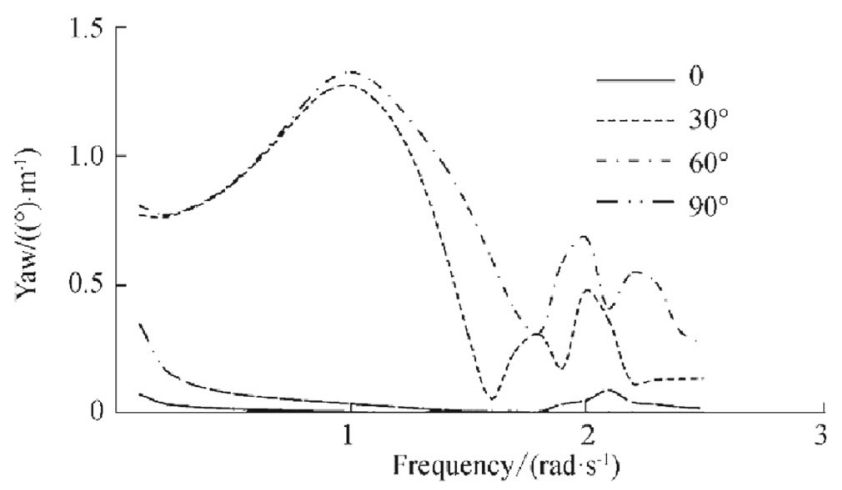

(f) RAO in yaw

angle was $0^{\circ}$ and $90^{\circ}$. In general, the RAOs of the device were below six in the wave energy concentration frequency range. The designed platform displayed fine

Table $10 \quad C_{y y}$ hydrodynamic coefficient

\begin{tabular}{lllllllllll}
\hline$\lambda$ & $c_{y y}^{0}$ & $c_{y y}^{1}$ & $\psi_{y y}^{1}$ & $n_{y y}^{0}$ & $n_{y y}^{1}$ & $\psi_{n, y y}^{1}$ & $m_{y y}^{0}$ & $m_{y y}^{1}$ & $\psi_{m, y y}^{1}$ \\
\hline 3 & 0.07 & -1.15 & 12.87 & 1.45 & -1.15 & -61.10 & 0.02 & -0.07 & -101.52
\end{tabular} 
hydrodynamic performance and frequency interaction characteristics.

The free decay test of the device was also performed in the ANSYS-AQWA. The initial displacement of the device was given in three degrees of freedom, namely, rolling, pitch, and

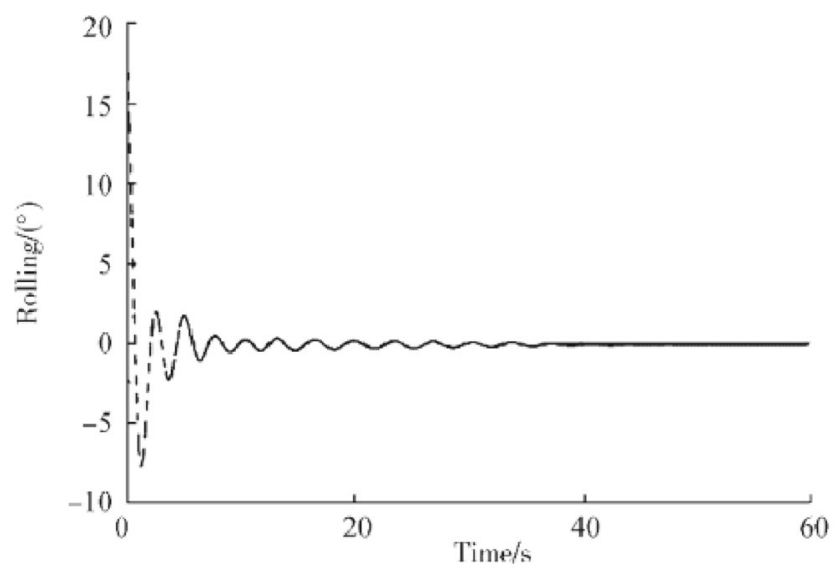

(a) Free decay curve of rolling

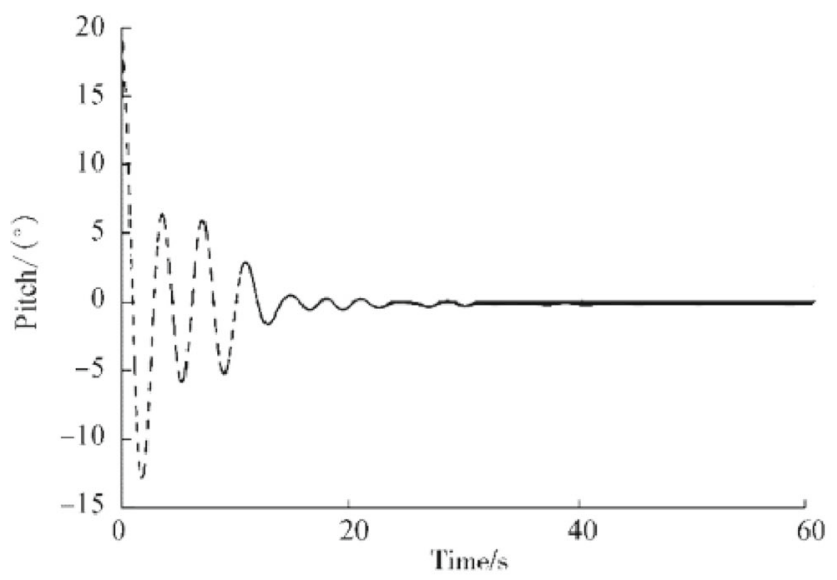

(b) Free decay curve of pitch

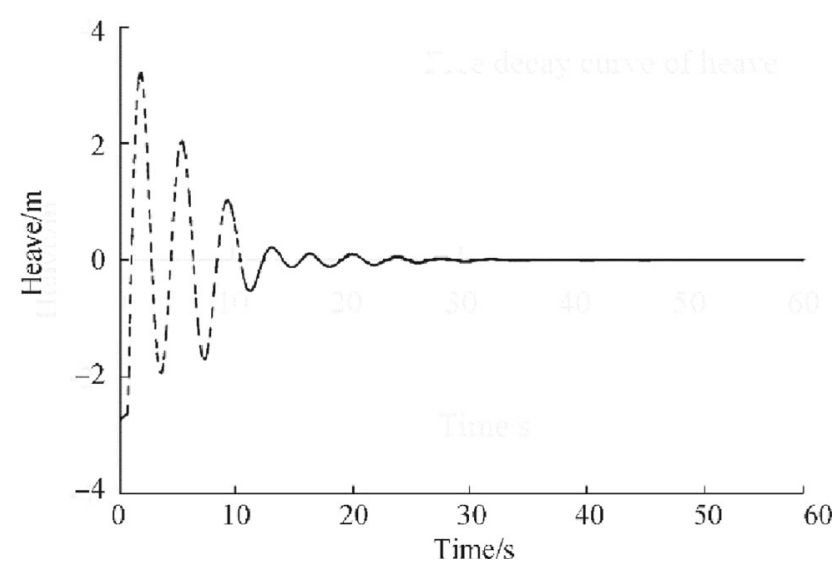

(c) Free decay curve of heave

Fig. 6 Free decay curve in different directions heave. The platform was then released freely. The numerical results obtained by AQWA-Line were transferred to AQWANaut. The free decay curves of the device were then obtained. The free decay curves of the device are shown in Fig. 6. Considering the invariant characteristics of the free decay curves, the specific period could be obtained. The natural periods of rolling, pitch, and heave were $2.6 \mathrm{~s}, 3.8 \mathrm{~s}$, and $3.5 \mathrm{~s}$, respectively, which were beyond the common wave frequency.

\subsection{Time-Domain Coupling Analysis}

The environment conditions of the ocean are quite complicated and the wind inflow direction of the floating power plant may be different from the wave direction. The influence of the direction of the waves on the floating tidal platform cannot be ignored. In order to fully verify the reliability and performance of the mooring system of the floating tidal platform, it was necessary to analyze the motion response of the platform and the tension of the mooring line under different wave incidence angles. As we can see from Fig. 3, the platform and the configuration of the mooring system were symmetrical about the $x-y$ plane; thus, the wave angles of $0^{\circ}, 30^{\circ}, 60^{\circ}, 90^{\circ}, 120^{\circ}$, $150^{\circ}$, and $180^{\circ}$ were chosen to perform the calculation process. The Joint North Sea Wave Project (JONSWAP) wave spectrum was selected for the calculation and the wave spectrum parameter $\lambda$ is equal to 3.3. The mean wave height and peak period were selected according to the design conditions. In order to reflect the normal working conditions of the platform, the inflow wind and current were taken to be at a $0^{\circ}$ incident angle. The calculation time was $5000 \mathrm{~s}$.

Figures 7 and 8 shows the time-domain curves of the sixdegrees-of-freedom motion of the platform with the greatest motion amplitude under different wave angles and the tension curve of the No. 2 mooring line with the maximum tension along with time.

As we can see from the displacement of the platform, the platform had undergone great changes in the horizontal plane due to the mooring line break. The lateral mean displacement increased to $-3.55 \mathrm{~m}$ when the wave angle was $150^{\circ}$. The maximum longitudinal displacement of the platform reached $-9.35 \mathrm{~m}$ when the wave angle was $60^{\circ}$. However, the surge value was still acceptable, accounting for the mooring line breakage and the designed sea area. The platform will not collide with the neighboring platform. The average value of the heave response was $3.32 \mathrm{~m}$ when the wave angle was $60^{\circ}$, which changed little compared with the value of the designed working condition. In the case of $180^{\circ}$ incident wave direction, the minimum drift was $4.68 \mathrm{~m}$ and the maximum drift was $6.32 \mathrm{~m}$. The turbine could always remain below the surface of the water, and the air gap height also met the safety requirements. On the whole, the platform finally 


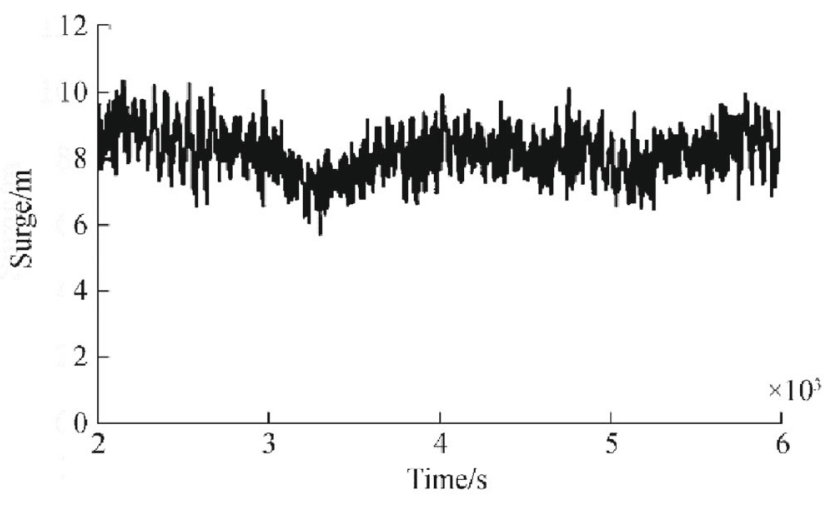

(a) Surge response curve

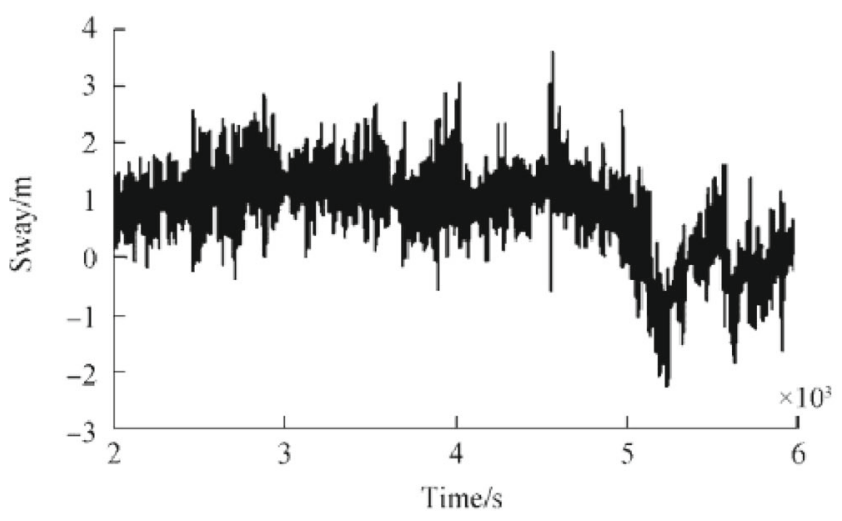

(b) Sway response curve

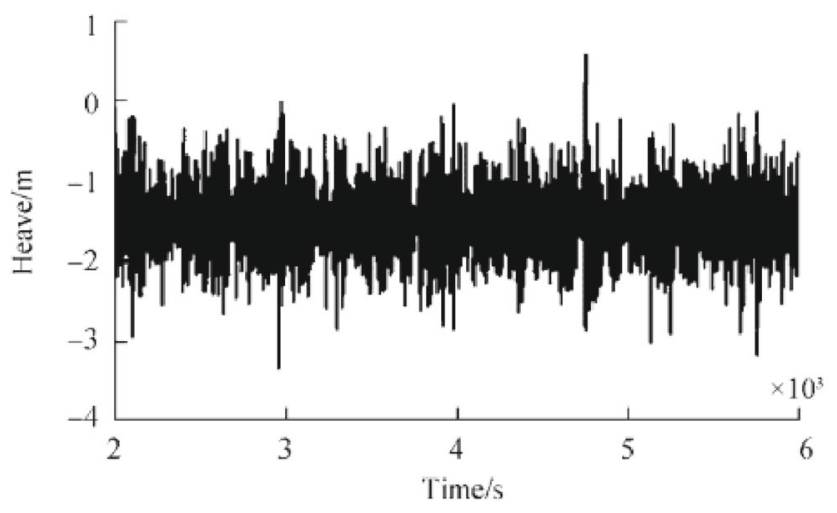

(c) Heave response curve

Fig. 7 Motion response in time domain

reached a new equilibrium position after the drift. The platform had undergone bigger offset in the minus $x$ direction and the drift was deeper. The offset value in the $y$ direction changed little. The oscillation amplitude in each direction was not very great. We did not consider the disconnection of the power cable due to large horizontal offset. In reality, the platform may disconnect from the power cable. The tidal current and wind turbines may shut down due to the large offset. Therefore, the aerodynamic load and the thrust of the water turbine should be reconsidered.

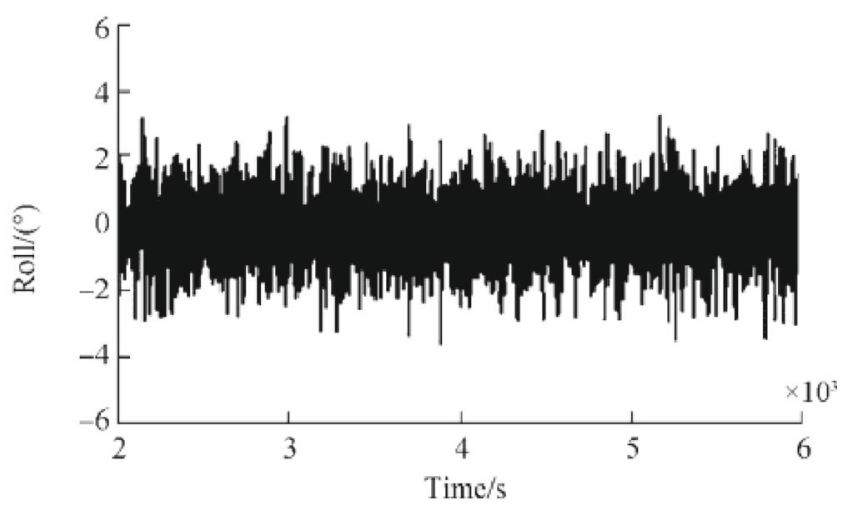

(d) Roll response curve

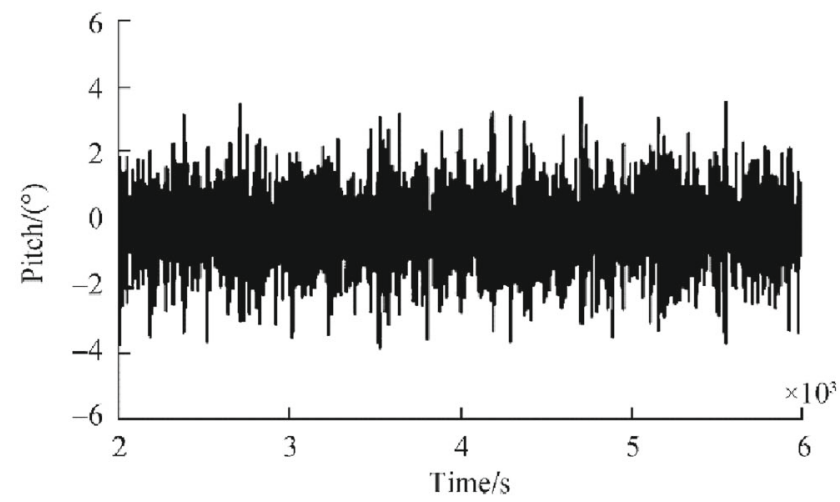

(e) Pitch response curve

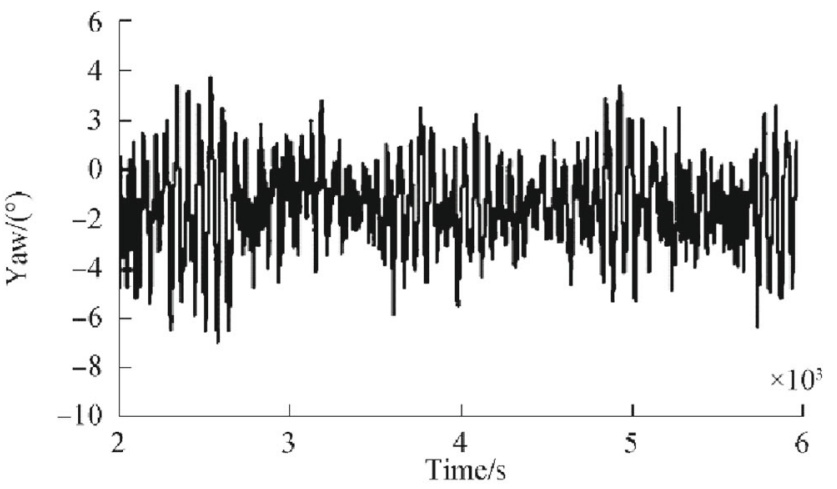

(f) Yaw response curve

The average pitch angle was about $0.35^{\circ}$ and the average roll angle was about -0.21 . The maximum pitch angle was $3.74^{\circ}$ and the maximum roll angle was $-3.51^{\circ}$. Compared with the designed working condition, the platform had undergone greater changes in the yaw freedom. The average yaw angle had significantly increased from 0.26 to $-2.21^{\circ}$ and the maximum yaw angle reached $-6.92^{\circ}$.

In summary, the positioning ability of the platform can still meet the requirements of the designed sea area once the mooring line breakage and the design of the mooring system are effective. 


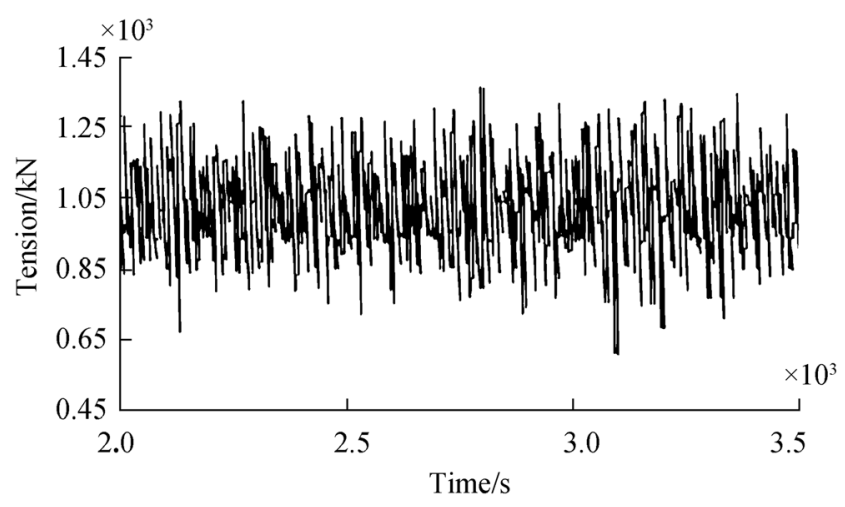

Fig. 8 No. 2 anchor chain tension response curve

\section{Conclusions}

This paper mainly studies the hydrodynamic performance of the semi-submersible wind-tidal combined power generation device. Our results show that: The motion of the device in the direction of the surge and sway is more intense, but the amplitude of the RAOs in the frequency range of the wave energy concentration is below 6 . Rolling, pitching, and heaving movements have the greatest impact on the power generation capacity of the device, and their RAOs' amplitude is below 4, which is in full compliance with the specification requirements. Also, it fully reflects the semi-submersible platform's excellent hydrodynamic performance and wave frequency reaction characteristics. Even under the worst conditions, the platform had undergone a large lateral offset and deflection that was biased toward the anchor chain, but the new equilibrium position was still within the acceptable range of the working area. Additionally, the platform still retained a large enough air gap height; the safety factor of the anchor chain tension also fully complied with the design specification requirements, which proves the safety of the mooring design. Under different working conditions, the platform swing amplitude was within the acceptable range, and completely avoided the path of the turbine blades above the surface of water, which proves that the platform is a smooth and efficient work platform.

Funding This paper was financially supported by the National Natural Science Foundation of China (Nos. 51779062; 51579055), the Fundamental Research Funds for the Central Universities of China (No. HEUCFP201714), and Shenzhen Special Fund for the future industries (No. JCYJ20160331163751413).

Open Access This article is distributed under the terms of the Creative Commons Attribution 4.0 International License (http:// creativecommons.org/licenses/by/4.0/), which permits unrestricted use, distribution, and reproduction in any medium, provided you give appropriate credit to the original author(s) and the source, provide a link to the Creative Commons license, and indicate if changes were made.

\section{References}

ANSYS AQWA (2013) User manual release 15.0, ANSYS Inc. https:// vdocuments.site/aqwa-users-manual.html

Chozas FJ (2012) Co-production of wave and wind power and its integration into electricity markets: case study: Wavestar and $525 \mathrm{~kW}$ turbine. The Annual Symposium of INORE, the International Network on Offshore Renewable Energy. http://www. icoe2012dublin.com/ICOE_2012/papers

Christensen ED, Stuiver M, Guanche R (2015) Go offshore-combining food and energy production. Technical University of Denmark. Department of Mechanical Engineering, Denmark. http://www. forskningsdatabasen.dk/catalog/2289698863

Deng H (2011) Study on stability and mooring system performance of offshore floating turbine foundation. Harbin Engineering University, Harbin (in Chinese). http://cdmd.cnki.co-m.cn/Article/CDMD10217-1012517714.htm

Greaves D, Iglesias G, Astariz S, Abanades J, Iglesias (2014) Co-located wave and offshore wind farms: a preliminary case study of a hybrid array. https://docplayer.net/9022055-Co-located-wave-andoffshore-wind-farms-a-preliminary-case-study-of-an-hybrid-array. html

Guo X, Liang Z (2013) The elastic mooring design of tidal current generation power device. Appl Sci Technol 40(3):6-9 (in Chinese). https://doi.org/10.3969/j.issn.1009-671X.201210018

Jiang D (2012) The general design of $150 \mathrm{~kW}$ semi-submersible tidal current power station. Harbin Engineering University, Harbin (in Chinese). http://cdmd.cnki.com.cn/Article/CDMD-102171012518177.htm

Li T (2017a) Coupling hydrodynamic analysis of vertical axis dual rotor floating tidal current generator. Harbin Engineering University, Harbin (in Chinese). http://cdmd.cnki.com.cn/Article/CDMD10217-1018075028.htm

Li Y (2017b) Research on the interference in vertical axis tidal turbine array based on OpenFOAM [D]. Harbin Engineering University, Harbin (in Chinese). http://cdmd.cnki.com.cn/Article/CDMD10217-1018081962.htm

Li Fenglai, Zhang Liang, Zhang Hongyu (2000) Research on 70KW water turbine of power station. National 863 Technology Report. Harbin Engineering University:5-6. (in Chinese). http://www.cnki. com.cn/Article/CJFDTotal-ZGDL200209042.htm

Lin WM, Yue DKP (1991) Numerical solutions for large amplitude ship motions in the time domain. Ship Motion, https://ci.nii.ac.jp/naid/ 10008213241

Ma Y, Tengfei L, Heng Z (2016) Design and strength analysis of floating three - cylinder power generation system. Ship Engineering 4:4346. (in Chinese). https://doi.org/10.13788/j.cnki.cbgc.2016.04.043

Marquis L, Kramer M, Kringelum J, Chozas JF, Helstrup (2012) Introduction of Wavestar wave energy converters at the Danish offshore wind power plant Horns Rev 2. 4th International Conference on Ocean Energy. http://vbn.aau.dk/da/publications/introduction-ofwavestar-wave-energy-converters-at-the-danish-offshore-windpower-plant-horns-rev-2(d5612ca3-d44d-462e-beabfa73a263ffd2).html

Mohanty A, Viswavandya M, Ray PK, Monhanty S (2016) Reactive power control and optimisation of hybrid off shore tidal turbine with system uncertainties. J Ocean Eng Sci 1(4):256-267. https://doi.org/ 10.1016/j.joes.2016.06.005

Pérez-Collazo C, Greaves D, Iglesias G (2015) A review of combined wave and offshore wind energy [J]. Renew Sust Energ Rev 42:141153. https://doi.org/10.1016/j.rser.2014.09.032

Qi QI, ZHANG T, WEN P (2011) Numerical simulation of FPSO mooring systems based on AQWA. Ship Sci Technol 12:004. https://doi. org/10.3404/j.issn.1672-7649.2011.12.003 
Quevedo E, Cartón M, Delory E (2013) Multi-use offshore platform configurations in the scope of the FP7 TROPOS project. OCEANS-Bergen, MTS/IEEE IEEE: 1-7. https://doi.org/10.1109/ OCEANS-Bergen.2013.6608061

Riefolo L, Lanfredi C, Azzellino A, Vicinanza D, Tomasicchio GR, D'Alessandro F, Penchev V (2016) Offshore wind turbines: an overview of the effects on the marine environment. ISOPE International Society of Offshore and Polar Engineers Rhodes (Rodos), Greece, pp 427-434

Sheng Qihu, Luo Qinjie, Zhang Liang (2008) Design on the carrier of $40 \mathrm{~kW}$ tidal current power station. The first symposium of the Committee on Marine Energy of the China Renewable Energy Society, Hangzhou: 159-168. (in Chinese). http://cpfd.cnki.com.cn/ Article/CPFDTOTAL-KZSH200803001019.htm

Sheng Q, Ke S, Xuewei Z (2014) Numerical methods of hydrodynamic analysis on tidal current turbines. J Ocean Technol 33(4):105-111 (in Chinese). http://or.nsfc.gov.cn/handle/00001903-5/291051

Sheng Q, Nianfu Z, Xuewei Z (2015) Hydrodynamic performance analysis of a $2 \mathrm{D}$ vertical current turbine with forced oscillation. J Harbin Eng Univ 01:41-45 (in Chinese). https://doi.org/10.3969/j.issn. 1006-7043.201312038

Tomasicchio GR, Avossa AM, Riefolo L, Ricciardelli F, Musci E, D'Alessandro F, Vicinanza D (2017) Dynamic modelling of a spar buoy wind turbine. Proc. 36th Int. Conf. on Ocean, Offshore and Arctic Engineering, American Society of Mechanical Engineering (ASME), Trondheim, Norway, n. OMAE2017-62246, V010T09A083-V010T09A093. https://doi.org/10.1115/ OMAE2017-62246

Tuitman JT, Malenica Š, Riaan VV (2012) Generalized modes in timedomain seakeeping calculations. J Ship Res 56(4):215-233. https:// doi.org/10.5957/JOSR.56.4.100034

Wang Zhichao (2011) Overall scheme design of floating power station. Dissertation Harbin Engineering University (in Chinese). https://doi. org/10.7666/d.y2053411

Zhang L, Wu H, Fengmei J (2010) Study on offshore floating wind turbine and its development. J Ocean Technol 29(4):122-126. (in Chinese). https://doi.org/10.3969/j.issn.1003-2029.2010.04.027

Zhang L, Xinzhong L, Jing G (2013) Tidal current energy. Adv New Renew Energy 1(1):53-68. (in Chinese). https://doi.org/10.3969/j. issn.2095-560X.2013.01.006

Zhu Dianming, Li Fenglai, Zhang Liang (2002) 70kW-Tidal current experimental power station. Harbin Engineering University Technical Report, 96-A17-06-03. (in Chinese). http://www.cnki.com.cn/ Article/CJFDTotal-zgdl200209042.htm 